\title{
Evaluation of Selected Risk Categories Related to Marketing Activities by SMEs in Case of Potential Cluster Cooperation
}

\author{
Katarina Haviernikova ${ }^{\mathrm{a}, *}$, Eva Ivanova ${ }^{\mathrm{b}}$ \\ Faculty of Social and Economic Relations \\ Alexander Dubcek University of Trencin \\ Trencin, Slovakia \\ katarina.haviernikova@tnuni.sk ${ }^{\mathrm{a}, *}$ \\ eva.ivanova@tnuni.sk
}

\begin{abstract}
Small and medium sized enterprises (SMEs) represent the largest group of stakeholders in Slovak clusters. The connection of SMEs into cluster cooperation depends on the base of knowledge that the owners/managers in SMEs dispose. The results of this paper contribute to the widespread of these knowledge. The main aim of this paper is to evaluate which selected risks categories related to marketing activities are recognized by SMEs in case of potential cluster cooperation as the most risky. Evaluated were four risk categories: 1. Analysis of competition, 2. Market analysis, 3. Quality and 4. The production of clusters. We used the questionnaire method with a selection of respondents with experience or knowledge of cluster cooperation. The respondents' answers were examined by dividing into two groups according: size category of SMEs and affiliation to the technological or tourism orientation of their activities. Further we used descriptive statistics and our hypotheses have been evaluated by corresponding statistical tests for analysis of variance. The findings showed the differences in evaluation of risk categories by SMEs depending on the type of their activities, not size category.
\end{abstract}

Keywords-Cluster; Small and medium sized enterprises; Risks; Evaluation; Marketing activities; Competition; Market; Quality; Production

\section{INTRODUCTION}

Each entity (business entity, an individual person, an educational institution, a self-government body, etc.) is located and carries out its activities in an environment that is dynamic, continuously develops, it is influenced by various internal and external factors, and thus it is exposed to a certain risk. Risk is defined in a context that is directly related to. Risk has a different importance for different activities. It is connected with uncertainty with which the activities of the entities are linked. In this paper as an entity on which the different risk factors affect, we considered the involvement of regional actors (SMEs) in network cooperation in the form of a cluster. The concept of cluster is based on the principle of network cooperation. Cooperation of businesses by their involvement in business networks appears to be a suitable tool to maintain market position in the market and to increase their innovation performance. [1] In literature, we can find many other definitions of regional clusters. The regional cluster can be defined as the geographic proximity of firms in the same industry linked by complementary commonalities [2] Regional clusters are identified as drivers of innovation and economic growth because the clusters' structure creates favorable conditions for open innovation, promoting cooperation among different market actors in the process of creating innovation, combining complementary skills and competences and involving users in the development of innovative solutions (user-driven innovation). [3] Clusters also play important role in organization of common marketing that is the spontaneous cooperation of enterprises within the cluster market behaviour, to transform co-marketing awareness into concrete action of the cluster.[4] In recent years, the importance of clusters was confirmed mainly for SMEs as well as at company's and at national macroeconomic level. [5] SMEs require special attention as their ratio on individual markets is between 9599\%. Similar is the situation in the EU, where SMEs form the backbone of the economy. [6] SMEs are dynamic elements of the market, they provide employment in those areas where are no larger companies for various reasons, they flexibly respond to market conditions and introduce many innovations. [7] It might be the reason, why small firms mostly grow faster than their larger counterparts. [8] On the other hand, they are far more vulnerable than large enterprises. They are sensitive to changes in market conditions. [9] For SMEs, it is adequate to apply a system approach in managing the innovation activities. $[10,11]$ Lability in the external environment - fluctuations in raw material and energy prices, inflation, exchange rate fluctuations, changes in the economic policies of states, transformation in technological environment and the rise in international competition have led to the fact that traditional methods of organizing and managing businesses for SMEs make significant changes. Behind these conditions, SMEs seek to use in addition to the advantages of specialization, provide production co-operation, production expansion, joint research and development, and also financial risk distribution Only combined efforts in a wide range of directions can be small businesses to count on a stable situation in the structure of the economy, with successful competition and working with large companies in case of cluster cooperation.

Clusters carry out their activities within the internal (cluster management, organizational structure, processes arising in cluster, relationships among entities, etc.) and 
external environment (framework, where the implementation of cluster activities is executing, consisting of factors package: natural, cultural, social, economic, technological, political, legislative, not only at the governmental level, but also at the regional level). From this point of view, we can observe the risks influenced from cluster cooperation from two perspectives: the existence of an external threat (external risks) and risk associated with its own activities (internal risks). [12] Due to the stated above, within the scientific project VEGA realized at Faculty of Social and economic relations we focused on many risk factors that have impact on SMEs' decision about their involvement into cluster cooperation. Among observed risk factors, the risk categories related to marketing issues were also evaluated. The concept of cluster cooperation is a well-known topic in the Slovak Republic, although the involvement of regional actors in this form of cooperation is limited. There are many reasons, but one that is important is the lack of information. This paper contributes to the widespread of information about advantages of cluster cooperation mainly for SMEs towards issue of risks associated to marketing.

\section{METHODOLOGICAL APPROACH}

Towards achieving of main aim of this paper, that is evaluation of selected risks that are related to marketing activities recognized by SMEs in case of potential cluster cooperation, the questionnaire surveys were realized in years $2016-2018$. The surveys were realized between two types of SMEs in the context of Slovak cluster typology: technological and tourism. This typology was also used in project VEGA within the frame this paper was created. Technological clusters carry out their activities in the following areas: ICT, creative industry, bio-economic focus, agriculture and food, engineering, energy, electrical engineering, construction, automotive, scientific research, and so on. This type of enterprises is important for economic development of regions because technology is a double-edged sword for business offering many opportunities but also challenges. On one hand, it opens up a variety of opportunities for business in terms of new products, processes, and markets. On the other hand, it leaves firms more open to a range of competitive threats such as takeover, increased competition and even to the theft of their technologies. [13] Clusters operating in tourism area are the second important type of Slovak clusters. Tourism, primarily in industrialized countries, has been one of the key manufacturing industries, notably contributing to the Gross Domestic Product (GDP), offering relatively attractive employment options and reaching a substantial proportion within the employment structure. [14]

Slovak republic consist of eight self-governing regions: Bratislava - BA, Trnava - TT, Trenčín - TN, Nitra -NR, Zilina - ZA, Banská Bystrica - BB, Košice - KE, Prešov - PO with 18 of technological clusters and 8 clusters of tourism. We can observe more than 140 SMEs in technological clusters and more than 30 SMEs in tourism clusters. Of this number, only around $50 \%$ took part in this research. This limitation of research leads to the diffusion of surveys among SMEs that have also experience/knowledge with this form of cooperation. This research covers the answers from 516 tourism and 471 technological SMEs. The structure of respondents represents Table I.

TABLE I. THE STRUCTURE OF RESPONDENTS - TOURISM SME

\begin{tabular}{|l|l|l|l|l|}
\hline Region & \multicolumn{1}{|c|}{ Micro } & \multicolumn{1}{|c|}{ Small } & \multicolumn{1}{|c|}{ Middle } & \multicolumn{1}{c|}{ Total } \\
\hline BA & $2.71 \%$ & $2.91 \%$ & $2.71 \%$ & $8.33 \%$ \\
\hline TT & $4.26 \%$ & $2.91 \%$ & $0.78 \%$ & $7.95 \%$ \\
\hline TN & $20.35 \%$ & $15.12 \%$ & $2.13 \%$ & $37.60 \%$ \\
\hline NR & $4.84 \%$ & $2.52 \%$ & $0.00 \%$ & $7.36 \%$ \\
\hline ZA & $11.43 \%$ & $10.66 \%$ & $1.16 \%$ & $23.26 \%$ \\
\hline BB & $2.52 \%$ & $1.16 \%$ & $0.19 \%$ & $3.88 \%$ \\
\hline KE & $4.65 \%$ & $3.49 \%$ & $0.78 \%$ & $8.91 \%$ \\
\hline PO & $1.36 \%$ & $1.36 \%$ & $0.00 \%$ & $2.71 \%$ \\
\hline Total & $52.13 \%$ & $40.12 \%$ & $7.75 \%$ & - \\
\hline \multicolumn{2}{|l|}{ a. Source: own research, micro (0-9 employees), Small (10-49 employees), Middle (50-249 } \\
employes)
\end{tabular}

From the point of view of regional location of respondents, the largest group was from Trenčín region (37.60\%) in case of tourism SMEs and $(35.59 \%)$ in case of technological SMEs. From the point of view of size categorization in case of both types of SMEs it was category of micro enterprises with max. 9 employees. (see Table I. and Table II).

TABLE II. THE STRUCTURE OF RESPONDENTS - TECHNOLOGICAL SME

\begin{tabular}{|l|l|l|l|l|}
\hline \multicolumn{1}{|c|}{ Region } & \multicolumn{1}{c|}{ Micro } & \multicolumn{1}{c|}{ Small } & \multicolumn{1}{c|}{ Middle } & \multicolumn{1}{c|}{ Total } \\
\hline BA & $3.18 \%$ & $4.87 \%$ & $2.75 \%$ & $10.81 \%$ \\
\hline TT & $2.12 \%$ & $4.24 \%$ & $2.75 \%$ & $9.11 \%$ \\
\hline TN & $13.56 \%$ & $11.44 \%$ & $10.59 \%$ & $35.59 \%$ \\
\hline NR & $2.33 \%$ & $1.91 \%$ & $2.75 \%$ & $6.99 \%$ \\
\hline ZA & $8.26 \%$ & $6.36 \%$ & $6.99 \%$ & $21.61 \%$ \\
\hline BB & $2.33 \%$ & $1.27 \%$ & $1.69 \%$ & $5.30 \%$ \\
\hline KE & $3.18 \%$ & $2.33 \%$ & $2.12 \%$ & $7.63 \%$ \\
\hline PO & $0.64 \%$ & $1.48 \%$ & $0.85 \%$ & $2.97 \%$ \\
\hline Total & $35.59 \%$ & $33.90 \%$ & $30.51 \%$ & - \\
\hline \multicolumn{2}{|l|}{ b. Source: own research, micro (0-9 employees), Small (10-49 employees), Middle (50-249 } \\
\end{tabular}
employees)

Based on the literature review $[12,15,16]$ we classified within our research four categories of risks that have connection among marketing in case of SMEs' connection into cluster cooperation: 1. Analysis of competition, 2. Market analysis, 3. Quality, 4. Production of clusters.

We followed the perception of these risks by respondents, how much they are important for them from point of view of join the cluster cooperation. The using of analysis of variance of the selected risks can be determined by whether their perception in the SMEs categories is identical. It is comparable to see whether the category of SMEs affects their assessment of selected risks when they are considering their participation in cluster cooperation. A subjective perception of respondents was assigned by values on Likert scale from $0-$ insignificant to 5 - the most important. We have used empirical research methods (questionnaire surveys), a statistical method that is analysis of variance using 
quantitative tool of statistics (percentages, Shapiro-Wilk test, Levene's test, Kruskal-Wallis test). Following [17], we have used the quantitative method known as the ANOVA - analysis of variance. We have determined the analysis of variance of either a parametric or a nonparametric test. Two basic conditions had to be met for the calculation of the parametric test: normality and homogeneity of variance. We have used the Shapiro-Wilk test to verify normality, with a null hypothesis $\mathrm{H} 0$ : random selection $\mathrm{X}_{1}, \mathrm{X}_{2}, . ., \mathrm{X}_{\mathrm{n}}$ originates from a basic set with normal distribution against the alternative hypothesis H1: the selection comes from a basic file with another layout. Calculated test statistic we compared to the corresponding $\mathrm{p}$-value. In the case that the p-value is greater than the chosen significance level $\alpha=0.05$, the hypothesis H0 is not rejected. Otherwise, we accepted alternative hypothesis $\mathrm{H} 1$ at the level of significance $\alpha$. The calculation was carried out in the program STATISTICA. To test the homogeneity of variance we have used the Levene's test. This test is used if $k$ samples have equal variances. By Levene's test we tested null hypothesis H0: We assume that variables in populations do not differ H0: $\sigma_{1}{ }^{2}=\sigma_{2}{ }^{2}=\ldots=\sigma_{\mathrm{n}}{ }^{2}$ against alternative hypothesis $\mathrm{H} 1$ : $\sigma_{1}^{2} \neq \sigma_{2}^{2} \neq \ldots \ldots \neq \sigma_{n}^{2}$ that claims, that at least one pair of variances is different. The significance level is $\alpha=0.05$. If the result of p-value is higher than $\alpha$, the $\mathrm{H} 0$ is accepted. In otherwise the $\mathrm{H} 1$ is valid.

\section{RESULTS}

The necessary information for analysis of variance is given in Table III. These are the basic statistical characteristics: the average of respondents' evaluation, the range of respondents' evaluation, standard deviation.

TABLE III. DESCRIPTIVE STATISTICS OF RESEARCH VARIABLES

\begin{tabular}{|l|l|l|l|l|l|l|}
\hline \multirow{2}{*}{$\begin{array}{c}\text { Risk } \\
\text { category }\end{array}$} & $\begin{array}{c}\text { The average of } \\
\text { respondents' } \\
\text { evaluation }\end{array}$ & \multicolumn{2}{c|}{$\begin{array}{c}\text { The range of } \\
\text { respondents' } \\
\text { evaluation }\end{array}$} & \multicolumn{2}{|c|}{$\begin{array}{c}\text { Standard } \\
\text { deviation }\end{array}$} \\
\cline { 2 - 7 } & $\begin{array}{c}\text { TO } \\
(\mathbf{5 1 6})\end{array}$ & $\begin{array}{c}\text { TE } \\
\mathbf{( 4 7 1 )}\end{array}$ & $\begin{array}{c}\text { TO } \\
(\mathbf{5 1 6})\end{array}$ & $\begin{array}{c}\text { TE } \\
\mathbf{( 4 7 1 )}\end{array}$ & $\begin{array}{c}\text { TO } \\
(\mathbf{5 1 6})\end{array}$ & $\begin{array}{c}\text { TE } \\
\mathbf{( 4 7 1 )}\end{array}$ \\
\hline 1. & 2.63 & 3.33 & 1.85 & 1.63 & 1.36 & 1.28 \\
\hline 2. & 2.53 & 2.81 & 1.87 & 1.58 & 1.37 & 1.26 \\
\hline 3. & 3.28 & 3.30 & 2.24 & 2.16 & 1.50 & 1.47 \\
\hline 4. & 2.31 & 2.65 & 2.00 & 1.90 & 1.41 & 1.38 \\
\hline
\end{tabular}

Source: own
calculation

In case of tourism SMEs, as the most risk category was marked by respondents the category of 3. Quality $(3, .8 \pm 1.50)$. In case of technological SMEs it was category 1. Analysis of competition $(3.33 \pm 1.28)$.

The analysis of variance by using the parametric statistic ANOVA could be used if two preconditions are fulfill - the homogeneity and the normality. If these conditions are not met, a nonparametric test is required. Table IV. and Table V. present the test results of homogeneity and the normality. For findings, if the homogeneity of data is present the Levene's test was used. For findings, if the data came from normal distribution, the Shapiro-Wilk test was used. These tests were realized in two ways: separately for data from tourism and technological SMEs and together, for data from both types of enterprises. $\mathrm{T}$

TABLE IV. THE RESULTS OF LEVENE'S TEST

\begin{tabular}{|l|l|l|l|}
\hline \multirow{2}{*}{ Risk category } & \multicolumn{3}{|c|}{ Levene's test (p-value) } \\
\cline { 2 - 4 } & \multicolumn{1}{|c|}{ TO(515) } & \multicolumn{1}{|c|}{ TE(471) } & TO/TE (987) \\
\hline 1. & 0.987135 & 0.803895 & 0.045683 \\
\hline 2. & 0.438873 & 0.307090 & 0.001977 \\
\hline 3. & 0.540699 & 0.265299 & 0.524739 \\
\hline 4. & 0.769443 & 0.078899 & 0.254027 \\
\hline
\end{tabular}

If we analyzed data of respondents in each category of SMEs, the results of Levene's test showed that p-value is higher than significance level $\mathrm{p}>0.05$ for each of evaluated risks. In case of evaluation data in comparison technological and tourism in total, the results of this test showed, that pvalue is higher than significance level in case of two categories of risks: 3. Quality (0.53) and 4. Production of clusters $(0.25)$. The non-parametric test is compulsory for the rest of risk categories.

TABLE V. THE RESULTS OF SHAPIRO-WILK TEST

\begin{tabular}{|l|l|l|l|}
\hline \multirow{2}{*}{ Risk category } & \multicolumn{3}{|c|}{ Shapiro-Wilk test } \\
\cline { 2 - 4 } & \multicolumn{1}{|c|}{ TO(516) } & \multicolumn{1}{|c|}{ TE(471) } & \multicolumn{1}{|c|}{ TE (987) } \\
\hline \multirow{2}{*}{1.} & $\mathrm{~W}=0.93016$, & $\mathrm{W}=0.89100$, & $\mathrm{W}=0.91932$, \\
& $\mathrm{p}<0.0000$ & $\mathrm{p}<0.0000$ & $\mathrm{p}<0.0000$ \\
\hline \multirow{2}{*}{2.} & $\mathrm{~W}=0.93016$, & $\mathrm{W}=0.91828$, & $\mathrm{W}=0.92575$, \\
& $\mathrm{p}<0.0000$ & $\mathrm{p}<0.0000$ & $\mathrm{p}<0000$ \\
\hline \multirow{2}{*}{3.} & $\mathrm{~W}=0.88623$, & $\mathrm{W}=0.88527$, & $\mathrm{W}=0.88626$, \\
& $\mathrm{p}<0.000$ & $\mathrm{p}<0.000$ & $\mathrm{p}<0.000$ \\
\hline 4. & $\mathrm{~W}=0.93179$, & $\mathrm{W}=0.92590$, & $\mathrm{W}=0.93114$, \\
& $\mathrm{p}<0.0000$ & $\mathrm{p}<0.0000$ & $\mathrm{p}<0.0000$ \\
\hline
\end{tabular}

Source: own
calculation

By using the Shapiro-Wilk test in programme STATISTICA, we tested normality of research sample. The results are given in Table $\mathrm{V}$. The results showed that the calculated p-value is lower than the chosen significance level $(0.05)$ and therefore the hypothesis $\mathrm{H} 0$ about normality must be rejected and the alternative hypothesis $\mathrm{H} 1$ is accepted.

Due to the previous results, we note that the conditions were not met for the use of the parametric test, so we will use the non-parametric Kruskal-Wallis test. The results are shown in Table VI. The authors tested two null hypothesis $\mathrm{H}_{1}$ : The difference in mean values at particular risk among the type of SME according their size is not statistically significant; and $\mathrm{HO}_{2}$ : The difference in mean values at particular risk among the type of SME's activity (technological or tourism) is not statistically significant.

The calculated p-value for $\mathrm{H}_{1}$ of the analysis of intensity variance of risk categories is higher than 0.05 for all risk categories and for $\mathrm{HO}_{2}$ only in case of $3^{\text {rd }}$ risk category (Quality). In these cases, the H0 was not rejected. The authors admit the 0.95 probability of reliability that among the individual responses of the respondents in the surveyed SMEs the difference in mean values is not statistically significant. 
The $\mathrm{HO}_{2}$ is rejected for risk categories: 1. Analysis of competition, 2. Market analysis, and 4. Production of clusters.

TABLE VI. THE RESULTS OF KRUSKAL-WALLIS TEST

\begin{tabular}{|c|c|c|c|}
\hline & \multicolumn{2}{|c|}{ KW test for $\mathrm{H} 01$} & KW test for $\mathrm{H} 02$ \\
\hline $\begin{array}{c}\text { Risk } \\
\text { categ. }\end{array}$ & TO(516) & $T E(471)$ & TO/TE (987) \\
\hline 1. & $\begin{array}{l}\mathrm{H} \quad(1, \quad \mathrm{~N}=516) \\
=0.10701 \\
\mathrm{p}=0.7436\end{array}$ & $\begin{array}{l}\mathrm{H} \quad(1, \quad \mathrm{~N}=471) \\
=1,3458 \\
\mathrm{p}=0.2460\end{array}$ & $\begin{array}{l}\mathrm{H} \quad(1, \quad \mathrm{~N}=987) \\
=71,258 \\
\mathrm{p}=0.0000\end{array}$ \\
\hline 2. & $\begin{array}{l}\mathrm{H} \quad(1, \quad \mathrm{~N}=516) \\
=0.1862 \\
\mathrm{p}=0.2761\end{array}$ & $\begin{array}{l}\mathrm{H} \quad(1, \quad \mathrm{~N}=471) \\
=1,9114 \\
\mathrm{p}=0.1668\end{array}$ & $\begin{array}{l}\mathrm{H} \quad(1, \quad \mathrm{~N}=987) \\
=11,3265 \\
\mathrm{p}=0.0008\end{array}$ \\
\hline 3. & $\begin{array}{l}\mathrm{H} \quad(1, \mathrm{~N}=516) \\
=0.53062 \\
\mathrm{p}=0.4663\end{array}$ & $\begin{array}{l}\mathrm{H} \quad(1, \quad \mathrm{~N}=471) \\
=0.11898 \\
\mathrm{p}=0.7301\end{array}$ & $\begin{array}{l}\mathrm{H} \quad(1, \quad \mathrm{~N}=987) \\
=, 04785 \\
\mathrm{p}=0.8268\end{array}$ \\
\hline 4. & $\begin{array}{l}\mathrm{H} \quad(1, \mathrm{~N}=516) \\
=0.57743 \\
\mathrm{p}=0.4473\end{array}$ & $\begin{array}{l}\mathrm{H} \quad(1, \quad \mathrm{~N}=471) \\
=1.4794 \\
\mathrm{p}=0.2239\end{array}$ & $\begin{array}{l}\mathrm{H} \quad(1, \quad \mathrm{~N}=987) \\
=14,968 \\
\mathrm{p}=0.0001\end{array}$ \\
\hline
\end{tabular}

\section{CONCLUSION}

Based on the results of realization of analysis of variance, when we used the non-parametric Kruskal-Wallis test, we can conclude, that statistical significant differences among respondents' answers we can observe if we take into account the whole research sample (987 SMEs) and the grouping factor is membership of a particular type of businesses. If we evaluated respondents' answers in the group of tourism and technological SMEs, individually, when the grouping factor was the size of company, we cannot confirm the statistical significant differences among sized category of SMEs in each observed type of business entities.

It was considered as the riskiest category in tourism SMEs (136 respondents) the category 3. Quality. This category was also marked by technological SMEs (131 respondents) as the riskiest category in case of potential engagement into cluster cooperation. In this category of respondents, we can observe another the riskiest category 1 . Analysis of competition that marked 151 respondents.

In an effort to respond flexibly and efficiently to the rapidly changing market situation by exploiting the potential of cluster cooperation (a comparative advantage), common marketing becomes one of the tools to create and maintain a competitive advantage for both SMEs and clusters. It represents a continuous social, change-oriented process. In cluster's marketing in the context of the set goals, attention is focused on promoting collaboration among all cluster's stakeholders, creating the conditions for an active market entrepreneurial approach to local and regional development and a common identity. The goal of implementing methods and tools of cluster's marketing is to shape the competitive advantage and creation of the cluster's position in the market.

\section{ACKNOWLEDGMENT}

VEGA [No 1/0918/16]: Risk management of SMEs in the context of clusters' involvement activities in the Slovak Republic.

\section{REFERENCES}

[1] L. Mura, R. Machová, and Z. Tóth, "Evaluation of innovation performance of the business networks," Hradec Economic Days, 2015, vol 5(5), pp. 41-47.

[2] Ch. Felzensztein, E. Gimmon, and K.R. Deans, "Coopetition in regional clusters: Keep calm and expect unexpected changes," Industrial Marketing Management, vol. 2018(69), pp.116-124

[3] R. Stasiak-Betlejewska, "Clusters as the element of eco-innovations promoting in the European construction on the Polish example," Acta Oeconomica Universitatis Selye, vol. 4(2), pp. 182 - 197, 2015.

[4] H. Tu, "Cluster Marketing Models and Strategies: The Implications Thereof in the Chinese High-Tech Industry," International Journal of China Marketing, vol. 1(2), pp. 34-45, 2011.

[5] E. Krajňáková and K. Krajčo, "The risk and clusters in the V4 countries and in the EU27" in 3rd International Multidisciplinary Scientific Conference on Social Sciences and Arts SGEM 2016: Political Sciences, Law, Finance, Economics and Tourism, Book 2, vol. III. Sofia: STEP92 Technology Ltd. pp.1135-1142.

[6] L. Mura, "Current situation in Family Businessen," Managerial trends in the development of enterprises in globalization era, 2017, pp. 178-185.

[7] Z. Caha, "The Extension of Education and Development for Company Managers in the Czech Republic", Vision 2020: Sustainable Economic development, Innovation Management, and Global Growth. Madrid: International Business Information Management Association, 2017, pp. 750-758.

[8] R. Fiala and V. Hedija, "Gibrat's law and empirical studies," 10th International Scientific Conference Financial management of Firms and Financial Institutions Conference Proceedings. Ostrava: VŠB Technical University of Ostrava, 2015, pp. 254-262.

[9] Z. Tóth and L. Mura, "Support for small and medium enterprises in the economic crisis in selected EU countries," Hradec Economic Days 2014: Economic Development and Management of Regions, PT V, 2014, pp. 424-429.

[10] M. Koval’ová, L. Hvolková, L. Klement, and V. Klementová, "Innovation strategies in the Slovak enterprises," Acta Oeconomica Universitatis Selye, vol. 7(1), pp. 79-89.

[11] E. Korcsmáros and E. Seres Huszárik, "Innovation activity of corporations," Acta Oeconomica Universitatis Selye, vol. 4(2), pp. $75-$ $83,2015$.

[12] K. Haviernikova, M. Okreglicka, and M.J. Klučka, Theoretical and Methodological Issues of Risk Management in Small and Medium-Sized Enterprises. Wien/Berlin: Mercur Verlag, 2016. pp. 201.

[13] M. Kordos and R. Karbach, "The issues of innovation in international economics," International Multidisciplinary Scientific Conferences on Social Sciences and Arts (SGEM 2014). Albena, Bulgaria. pp. 653+-.

[14] A. Grenčíková, S. Vojtovič, and M. Gullerová, "Staff qualification and the quality of tourism-related services in the Nitra region," Bulletin of Geography, vol. 2013 (21), pp. 41-48.

[15] C. Geldes, Ch. Felzensztein, E. Turkina, and A. Durannd, "How does proximity affect interfirm marketing cooperation? A study of an agribusiness cluster," Journal of Business Research, vol. 2015(68), pp. 263-272.

[16] M. Kordos, "Knowledge Economy Development in Global Economy Environment," 2016 2ND International Conference On Education And Management Science (ICEMS 2016), 2016, pp. 142-146.

[17] J. Betáková, R. Zeman, J. Dvorský, and T. Pavlenko, “Analysis Of Selected Risks Arising From Human Activities," The Handling Of Hazardous Waste, WIT Transactions on Ecology and the Environment, 2015, pp. 1. 